\title{
Notoedric Mange in a Domestic Cat: Application of Ivermectin and Supportive Therapy
}

\author{
Angel Alberto Florez Muñoz* and Juan Carlos Pinilla Leon
}

Universidad de Santander, Facultad de Ciencias Exactas, Naturales y Agropecuarias. Grupo de Investigación en Ciencias Agropecuarias-GICA, Bucaramanga, Colombia

*Corresponding author: angelflorezmvz@ hotmail.com

Article History: 20-246 Received: 14-Dec-20 Revised: 15-Jan-21 Accepted: 16-Jan-21
ABS T RA C T
Feline scabies is a disease that is caused by Notoedres cati, a sarcoptic mite that injures the skin tissue. The present
clinical case relates a notoedric scabies in a domestic cat, clinical observations, diagnostic test, and treatment. A 4-year-
old male neutered domestic short haired cat was brought at a veterinary clinic. Alopecia, erythema, scales, crusts and
hyperkeratosis were observed on the head, and pinnae and malodorous from lesions were observed in dermatological
examination. Deep skin scrapings were collected. Microscopic examination revealed adult live mites presence. Based
on the morphology, the mites isolated were identified as Notoedres cati. Ivermectin oral capsules $(300 \mu \mathrm{g} / \mathrm{kg})$, repeat
dose at 14 days. Bath with chlorhexidine and Benzoyl peroxide every 5 days for two months were applied. Moreover,
multivitamin complexes were supplied daily, orally. An immunostimulant $1 \mathrm{~mL} / 10 \mathrm{~kg}$. IM, again applied two days. A
clinical improvement in the cat was observed after administered this treatment. The present study reports notoedric
mange in a domestic short haired cat in Colombia. The application of ivermectin with supportive therapy was useful in
the treatment of notoedric scabies in this cat. The application of products other than ivermectin showed positive clinical
observations in the recovery of this patient with feline scabies.

Key words: Notoedres, Mange, Cat, Supportive therapy.

(C202I IJVS - All Rights Reserved

\section{INTRODUCTION}

Feline mange is a sickness produced by Notoedres cati, a sarcoptic mite that injures the skin tissue. This disease manifests clinically as intense pruritic, dry scab lesions that initially are observed on the pinna, and spreads quickly above ears, face, and neck (Meleau and Hnilico 2006). The laboratory diagnosis of the mites can be performed with deep skin scrapings and observation in optical microscopic, the mites are easily demonstrated. The clinical manifestations of notoedric mange are principally lack of hair and marked hyperkeratosis with large amount of epidermal flakes (Bowman 2014). It is a cosmopolitan disease and has been reported by several authors (Sivajothi et al. 2015b; Ngetich 2019; Stevanović et al. 2019). On the other hand, the application of products other than ivermectin has been shown to have positive effects on the recovery of the patient in feline scabies (Senthil et al. 2008; Reddy and Sivajothi 2014; Sivajothi et al. 2015b). Therefore, the objective of the present study is to report is a clinic case of notoedric mange in a domestic cat in Colombia, clinical observations, diagnostic tests, and treatment are informed and discussed. The application of ivermectin with supportive therapy was useful in the treatment of notoedric scabies in this cat. The application of products other than ivermectin showed positive clinical observations in the recovery of this patient with feline scabies.

\section{Case History, Examination and Treatment}

A 4-year-old male castrated domestic short haired feline was brought at the Teaching Veterinary Clinical Complex of the University of Santander, with a background of alopecia and intense pruritic, lethargy, and body weight loss. The cat was FIV/ feline leukaemia virus (FeLV) negative, had been dewormed, but ectoparasite control had not been used. The cat lived indoors in a house, but sometimes it to go outdoors it was often in direct contact with other stray cats. Alopecia, erythema, scales, crusts, and hyperkeratosis on the head and pinnae and malodorous from lesions were observed in the dermatology examination (Fig. 1). Clinical evaluation showed adenitis and high temperature $\left(40^{\circ} \mathrm{C}\right)$. Deep skin scrapings were taken from the skin wounds at different locations for laboratory analysis. Microscopic observation using Nikon ${ }^{\circledR}$ Eclipse E200 Vertical Trinocular Microscope Microscopic examination $(40 x)$ revealed the presence

Cite This Article as: Florez AAM and Leon JCP, 2021. Notoedric mange in a domestic cat: Application of ivermectin and supportive therapy. International Journal of Veterinary Science 10(4): 344-346. https://doi.org/10.47278/ journal.ijvs/2021.059 
Int J Vet Sci, 2021, 10(4): 344-346.

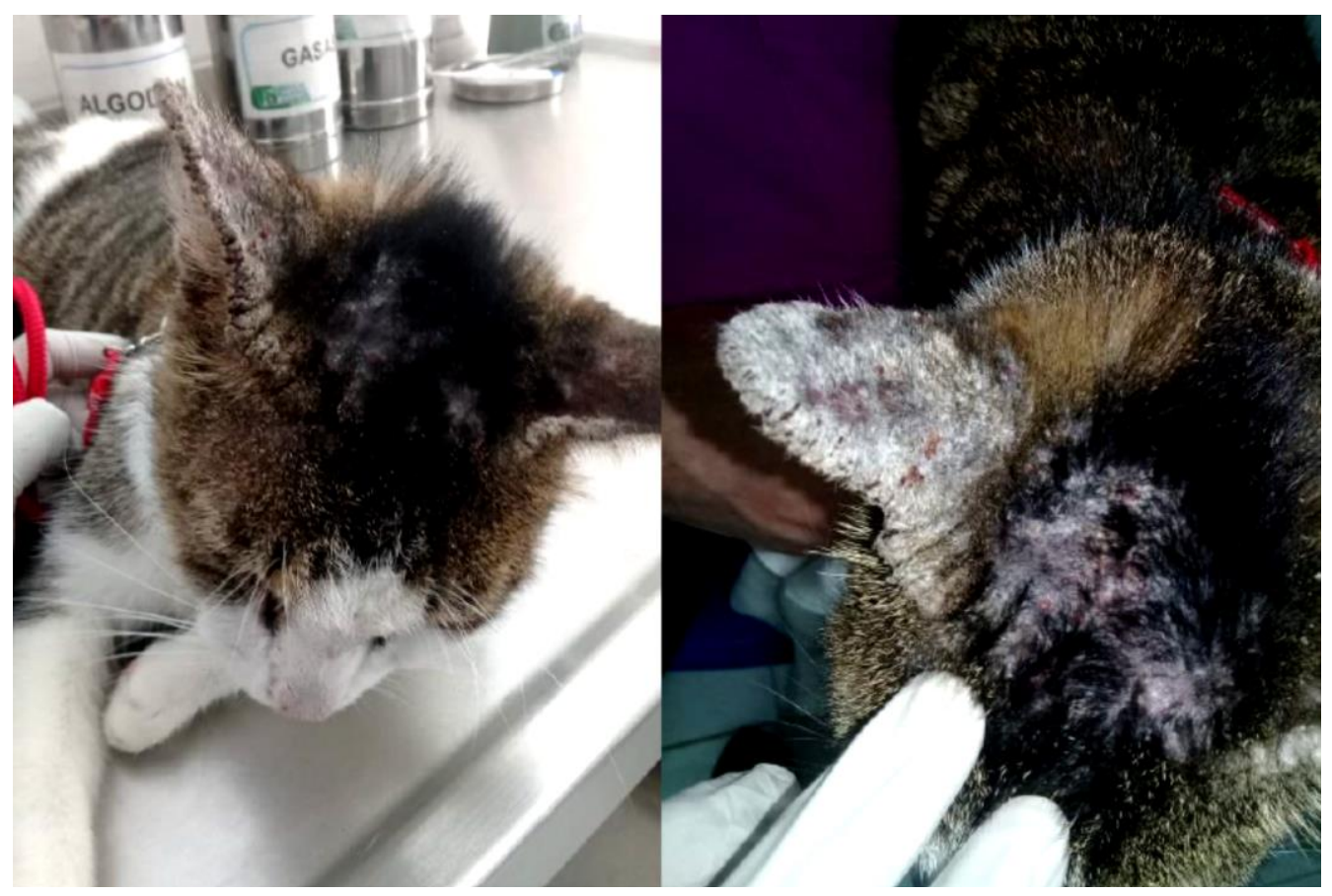

Fig. 1: Skin lesions over the head and pinnae of feline.

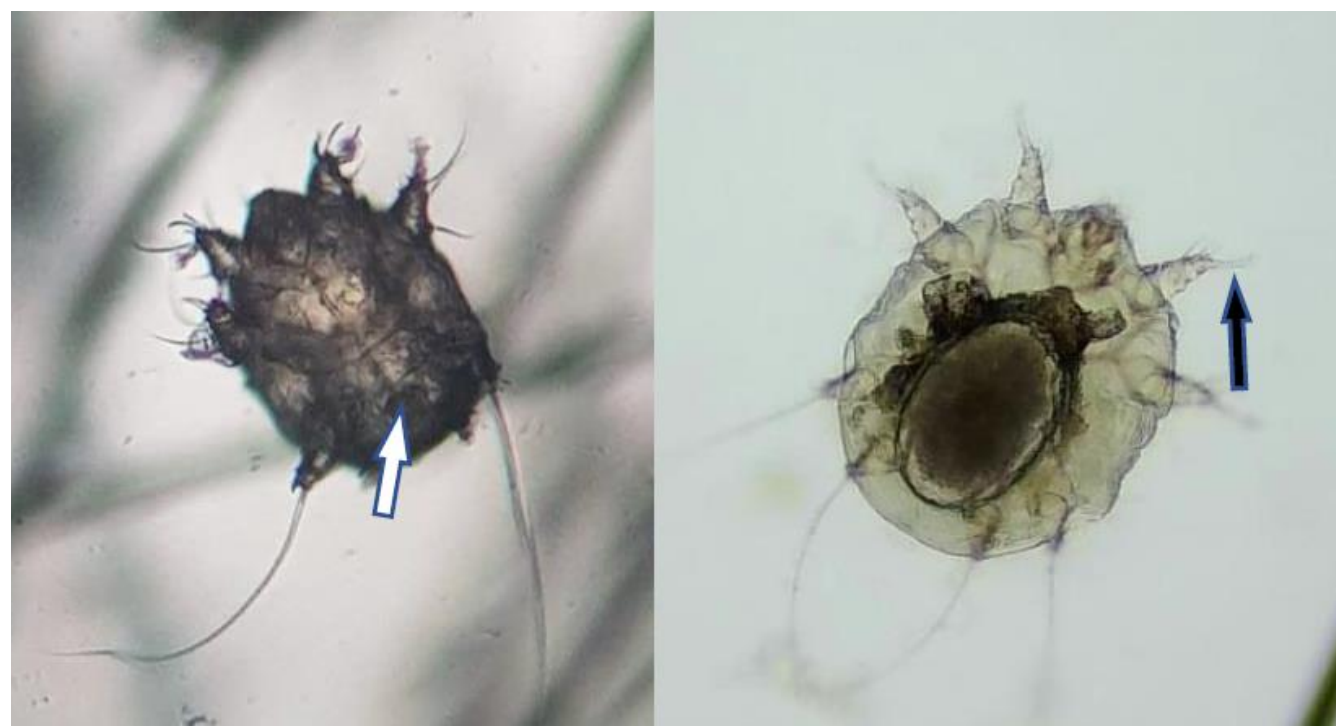

Fig. 2: Male (left) and female (right) adult mites in deep skin scraping morphologically compatible with Notoedres cati. Suckers on legs 1 and 2 (black arrow), and a dorsal anus (white arrow). 40x.

of live mites, features by a circular body, small legs, prolonged unjointed pedicels, and short square rostrum, suckers on legs 1 and 2 , with the dorsal anus, morphologically compatible with Notoedres cati adult mite (Fig. 2). No other parasites or fungal were observed in the clinical samples. Based on clinical observations and diagnostic tests used, the following treatment was instituted. Ivermectin oral capsules $(300 \mu \mathrm{g} / \mathrm{kg})$, repeat dose at 14 days (ivermectina ${ }^{\circledR}$ Laboratorios Calox Bogotá Colombia). Supportive therapy constituted by multivitamin complexes, bathing and immunostimulants were applied. Chlorhexidine bathing (Baxidin Spray®, Basic Farm laboratories S.A.; Bogotá-Colombia), Benzoyl peroxide (Peroxidex ${ }^{\circledR}$ Virbac Colombia LTDA) every 5 days for 2 months. Moreover, complex vitamins (Glicopan pet巴 Laboratorios VETNIL LTDA Brasil) once a day orally for two weeks. A stimulant of the immune system $(1 \mathrm{~mL} / 10 \mathrm{~kg})$ IM, again applicated in two days (INFERVAC® Laboratorios Calier de los Andes S. A. Bogotá - Colombia). No secondary clinical effects were observed following treatment with oral ivermectin and supportive therapy. The cat showed a notable improvement clinical after the applied treatment.

\section{DISCUSSION}

The present study reports notoedric mange in a domestic short haired cat in Colombia. Several studies has been reported about notoedric mange in domestic cats (Sivajothi et al. 2015b; Ngetich 2019; Stevanović et al. 2019). Based on the morphology, circular body, small legs, with prolonged unjointed pedicels, with a short square 
rostrum, suckers on legs 1 and 2 and a dorsal anus, females are about $225 \mu \mathrm{m}$ in length and males about $150 \mu \mathrm{m}$, the mites isolated were identified as Notoedres cati (Taylor et al. 2015). On the other hand, the clinical manifestations observed as alopecia, erythema, scales, crusts, was and hyperkeratosis on the head and pinnae and malodorous from lesions is agreed with other reports (Reddy and Sivajothi 2014; Sivajothi et al. 2015a; Ngetich 2019; Stevanović et al. 2019). The application of products other than ivermectin has been shown to have positive effects on the recovery of the patient in feline scabies (Senthil et al. 2008; Reddy and Sivajothi 2014; Sivajothi et al. 2015b). The application of the Benzoyl peroxide shampoo was effective against pruritus and hyperkeratosis, the signs, and symptoms reasons for consultation, due to its keratolytic action, and antimicrobial, anti-inflammatory, and sebostatic properties, this study agrees with a study carried out by Asl (2005). It is important to highlight, the application of products other than ivermectin should be administered to regulate the immune response in the patient, considering that immunosuppression is one factor to consider in the development of notoedric scabies (Foley et al. 2016). The application of ivermectin with supportive therapy was useful in the treatment of notoedric scabies in this cat. The application of products other than ivermectin showed positive results in the recovery of this patient with feline scabies.

\section{Conclusion}

The application of products other than ivermectin in the treatment of notoedric scabies in this cat showed positive results.

\section{Author's Contribution}

AAF and JCP collected the information, wrote, and edited the manuscript. All authors actively participated in the study and approved the final draft of this manuscript.

\section{REFERENCES}

Asl AS, 2005. Experimental study on different dosage of benzoyl peroxide effects on cat's wound healing. World Congress Proceedings; World Small Animal Veterinary Association; May 11-14, 2005, Mexico City, Mexico.

Bowman D, 2014. Georgis' Parasitology for Veterinarians. Arthropods: Chapter 2. $10^{\text {th }}$ Ed, Elsevier, Philadelphia, USA, pp: 68-69.

Foley J, Serieys L, Stephenson N, Riley S, Foley C, Jennings M, Wengert G, Vickers W, Boydston E, Lyren L, Moriarty J and Clifford D, 2016. A synthetic review of notoedres species mites and mange. Parasitology 143: 1847-1861. https://doi:10.1017/S0031182016001505

Meleau L and Hnilico K, 2006. Small Animal Dermatology: A Color Atlas and Therapeutic Guide. 2nd Ed, Elsevier's, St Louis, Missouri, USA, pp: 115.

Ngetich W, 2019. Mange in an adult domestic short haired catcase report. Archives of Animal Husbandry \& Dairy Science 1: 1-3. https://doi:10.33552/AAHDS.2019.01.000520

Reddy SB and Sivajothi S, 2014. Notoedric mange associated with Malassezia in cats. International Journal of Veterinary Health Science \& Research 02: 18-20 http://dx.doi.org/ 10.19070/2332-2748-140005

Senthil Kumar K, Selvaraj P, Vairamuthu S, Srinivasan SR and Kathiresan D, 2008. Ivermectin therapy in the management of notoedric mange in cats. Tamilnadu Journal Veterinary \& Animal Sciences 4: 240-241.

Sivajothi S, Reddy BS and Venkatasivakumar R, 2015a. Chronic dermatitis complicated with otitis due to Notoedres cati in a Persian cat. Journal of Advances of Parasitology 2: 19-22. http://doi.org/10.14737/journal.jap/2015/2.1.19.22

Sivajothi S, Redd B.S, Rayulu VC and Sreedevi C, 2015 b. Notoedres cati in cats and its management. Journal of Parasitic Diseases 39: 303-305. https://doi.org/10.1007/ s12639-013-0357-7

Stevanović O, Vujani D, Dobrijević M, Nedić D and Trbojević I, 2019. Notoedrosis in a household cat - case report. Archives of Veterinary Medicine 12: 39-47. https://doi.org/10.46784/ e-avm.v12i2.61

Taylor MA, Coop RL and Wall RL, 2015.Veterinary Parasitology, 4th Ed. Blackwell Scientific Ltd, Iowa, USA. 